\title{
FAMÍLIAS DE CRIANÇAS ACOMETIDAS POR DOENÇAS CRÔNICAS: REPRESENTAÇÕES SOCIAIS DA DOENÇA.
}

\author{
Maria Aparecida Crepaldi ${ }^{I}$
}

RESUMO:Este artigo trata de uma revisão bibliográfica sobre a participação de familiares no atendimento da criança hospitalizada e apresenta resultados parciais de um estudo que investigou as representações sociais que as famílias de crianças hospitalizadas, acometidas por doenças crônicas, têm sobre a doença e a hospitalização de seus filhos. Na enfermaria estudada, as famílias participavam de atividades especialmente destinadas à elas (programa mãe-participante), que visavam, fundamentalmente, a veiculação da informação. Para por em prática esta medida a equipe utilizavase de técnicas grupais. A população estudada constituiu-se de 38 famílias, perfazendo um total de 50 participantes e a metodologia de coleta de dados envolveu uma combinação de técnicas: observação participante de campo, observação sistemática e entrevistas. Os resultados indicaram que a primeira preocupação dos familiares é conhecer o diagnóstico, a representação da doença tem o sintoma como núcleo central e a hospitalização é vista inicialmente como uma experiência negativa.

Palavras chave: hospitalização, criança, família, doença crônica.

FAMILIES OF CHRONIC ILL CHILDREN: social representations of illness.

ABSTRACT: This article presents a review of literature of family participation in the assistance of hospitalized children, and presents, also, the partial results of a study that investigated families's social representations of their children's chronic illness and hospitalization. In the pediatric unit, parents were invited to participate in activities especially planned for them, whose aims were to convey and share information. To do so, the staff used group technique. The sample consisted of 38 families and the methodology of data collection was a combination of techniques such as systematic observation and interview. The results showed that family's main concern was the diagnosis, that the illness representation has the symptom as the main point, and that hospitalization is viewed firstly as a negative experience.

Keywords: hospitalization, child, family, chronic illnesse.

\footnotetext{
' Endereço para correspondência: Maria Aparecida Crepaldi, Laboratório de Educação e Saúde Popular, Departarnento de Psicologia, Universidade Federal de Santa Catarina. Avenida Othon Gama D'Eça. 809/904. CEP 88.015 - 240 Florianópolis, Santa Catarina. Fone (048) 331 8701 .
} 
Este artigo tem por objetivo abordar o tema da inserção de familiares no atendimento da criança enferma e que necessita de hospitalização, através de uma revisão da literatura, considerando os aspectos sobre os quais o tema se sedimenta. Além disso, pretende mostrar resultados parciais de uma pesquisa ${ }^{2}$ que investigou quais as representações sociais que familiares têm sobre a doença dos filhos, portadores de enfermidades crônicas.

Em se tratando da participação da família no atendimento da criança, ou de forma mais ampla, de sua integração ao processo de hospitalização, encontram-se na literatura muitos estudos referentes a crianças terminais, especialmente àquelas portadoras de leucemia (Alves, 1981; Evans, 1975; Friedman, 1967; Heffron, Bommelaere e Master, 1973; Thomas \& Cordell, 1983), ou com patologias graves. Nestes casos, as famílias recebem mais atenção, por se tratar de uma situação especial, além de se configurar para o hospital, realidade de difícil manejo.

No atendimento de crianças que apresentam patologias diversas e que, pelo menos, a princípio, não oferecem risco de vida, as famílias são vistas como um empecilho ao bom andamento dos serviços de assistência e encontram-se, na maioria das vezes, sem informação acerca do que está acontecendo.

As primeiras discussões sobre a participação de familiares no contexto hospitalar, datam da década de 50 e 60 e caracterizam-se pelo interesse em enfatizar as vantagens e desvantagens da admissão deles. A maioria dos estudos fundamentam-se nas pesquisas de Bowlby $(1952,1960)$ e Spitz (1945, 1946), sobre os efeitos nocivos da separação mãe-criança, e trazem inúmeras contribuições para os profissionais que atuam na instituição hospitalar e na área de saúde em geral.

Dentre esses autores, Coffin (1955), entrevistando enfermeiras em um hospital de clínica geral, constatou que todas concordavam que a presença de mães nas enfermarias pediátricas trazia benefícios, embora apontassem algumas objeções, como a necessidade de se ter um grande número de profissionais de enfermagem para atender, pois esta medida acarretava um ônus maior para os profissionais, que deveriam despender mais tempo para dedicarem-se também aos familiares. Coffin discute esta objeção, descrevendo sua experiência com horário irrestrito para visitas, pois em hospitais tradicionais o horário para a visitação é rigidamente estabelecido, e mostra as vantagens da adoção de tais medidas para as crianças: estas choram menos e parecem mais felizes,

${ }^{2}$ Este trabalho foi publicado na íntegra no livro: CREPALDI, M. A. Hospitalização na Infância: representaçöes sociais da familia sobre a doença e hospitalização dos filhos. Taubaté, Cabral Editora Universitária, 1999. 
enquanto que as mães podem aprender cuidados básicos. A autora contrapōese, ainda, ao argumento de que os familiares são responsáveis pela desorganização das enfermarias e agentes de indisciplina, o que é apresentado freqüentemente como justificativa para o alijamento dos pais.

Já na década de 50, Hohle (1957) afirmava que a lógica em trazer os pais para dentro do hospital era auto-evidente, primeiro porque são pessoas que favorecem o desenvolvimento da criança, são figuras de apego, são responsáveis pela criança e, como tal, deveriam ter direito a permanecerem ao lado dela em situação tão adversa. Portanto, não há outra razão maior do que a própria evidência para justificar a necessidade da presença deles. Esta autora assinala que nos hospitais privados não se discute este fato. Kazak (1997) reafirma esta idéia, evidenciando que a presença dos pais é inquestionável pelos mesmos motivos, acrescentando que familiares podem se constituir em coadjuvantes na assistência prestada.

Com a presença dos pais, ao contrário do que a equipe investigada por Coffin (1955) apontou, os profissionais ficam mais livres para fazer um trabatho de boa qualidade, já que estes podem ajudar nas atividades de cuidados. Há também maiores trocas entre o hospital e a comunidade (Fagin, 1962).

Roy (1968) afirma que apenas o contato da criança com a mãe não é suficiente, sendo necessário que ela possa responder às necessidades da mesma. A autora estudou as relações que se estabelecem entre enfermeiras e familiares e concluiu que a introdução proposital de tarefas, a serem cumpridas pela mãe, aumentam sua adequação. Acrescentaríamos a esta afirmação a idéia de que os pais podem prestar cuidados caso desejem, pois mantê-los para servir apenas como mão de obra gratuita, em substituição ao pessoal de enfermagem qualificado para exercer atividades de cuidados, é uma forma inadequada de fazê-los participar.

Conforme vários autores demonstraram, são inúmeros os benefícios trazidos pela presença dos pais, seja para a criança, para a equipe e para si próprios: evita a presença de reações emocionais causadas pela separação criança-família; faz a mediação entre equipe e criança; acelera a alta, uma vez que a convalescença é mais rápida; reduz a infeção cruzada, porque diminui o número de pessoas que manipulam a criança; diminui a incidência de problemas de pele porque os banhos e trocas de roupa são mais freqüentes; as crianças ficam mais calmas, choram menos e dormem melhor; fornece aos pais a possibilidade de continuar a exercer seu papel de cuidar do filho, o que ajuda no controle da ansiedade; os pais podem estar sempre bem informados sobre o que se passa com a criança e têm a oportunidade de aprender cuidados específicos; podem ajudar na observação constante do estado da criança; a equipe 
se beneficia porque pode observar a criança numa situação mais realística e pode estar mais disponível para atender às crianças sem acompanhantes (Andrade e Silva, Aguiar, Souza e Almeida, 1982; Cleary, Gray, Hall, Rowlandson, Sainsburg e Davis, 1986; Grünberg, Silva, Sitkewich, Esquivel e Farias, 1981; Issner, 1972; James \& Wheeler, 1969; Lisboa, 1973; Mac Carthy, 1981; Nascimento, 1985; Nolan, 1981; Osório, Ferari, Alonso e Cardoso, 1978; Ranna, 1987; Ryan, 1984; Schyff, 1979).

Muitas vezes, os pais são vistos como um problema na enfermaria, porque questionam, têm medo e sua presença é vista como um adicional da equipe absolutamente desnecessário. Os que se contrapõem a esta presença dizem que as crianças se comportam melhor quando os pais estão ausentes, $o$ que parece ser contraditório. É comum que a criança se torne mais exigente, chore, não aceite as intervenções dos profissionais e demonstre suas necessidades e desejos, assim protesta e nega-se a colaborar com os procedimentos realizados, o que ocorre mais freqüentemente na presença dos pais e pessoas com quem a criança tem familiaridade. Este padrão de comportamento é visto como indisciplina, é indesejável.

Por outro lado, na ausência dos familiares, a criança pode apresentarse apática e triste, o que faz com que aceite as intervenções sem protestar. Esta forma de comportar-se é vista, erroneamente, como adequada e pode até mesmo ser confundida com reações saudáveis, uma vez que a criança "não dá trabalho" (Hardgrove e Dawson, 1972).

Andrade e Silva e cols, (1982); Ayer , 1978; Grunberg e cols, ( 1981); Lisboa, 1973; MacCarthy, 1981, procuram rebater alegações de que os pais interferem na dieta da criança, aumentam o risco de infeção, tornam a relação com a criança mais difícil, são fonte de desordem, rebeldia e roubos na enfermaria, são agressivos e entram em atrito com os membros da equipe, além de contribuírem para o aumento do número de pessoas dificultando o trabalho.

É muito frequiente a alegação de que as enfermarias nāo dispõem de espaço físico e condições materiais para atender os pais adequadamente (Ayer, 1978), o que parece camuflar as razões verdadeiras para que se evite a sua admissão. A participação deles requer mudanças radicais na equipe de enfermagem (Mac Carthy, 1981).

Operar mudanças, porém, não é uma necessidade apenas da equipe de enfermagem, como refere Mac Carthy (1981), mas deve incluir os demais segmentos profissionais, a começar pelas chefias. Observamos que existe uma rigidez em relação à mudança na estrutura e organização dos hospitais, que procuram manter intactos os métodos tradicionais de funcionamento.

A presença de familiares força a adoção de uma forma diferente de 
funcionar que possibilita o atendimento da criança como um todo, a começar pela inclusão, na equipe, de outros profissionais não médicos que possam atender aos aspectos psicossociais da clientela, como: psicólogos, terapeutas ocupacionais, recreacionistas, assistentes sociais, nem sempre fácil de ser posta em prática, pois admitir a presença de uma equipe diversificada pressupõe a adoção de uma filosofia de atendimento que extrapola e questiona uma concepção da doença como circunscrita ao corpo, ou seja, considera uma visão mais ampla deste fenômeno, o que raramente é aceito pelo saber médico.

Segundo Ranna \& Okay (1980), a família é quem faz a ligação entre os diversos membros da equipe. Se esta última trabalha de forma desintegrada, as contradições tornam-se aparentes e os pais encarregar-se-ão de difundi-las, o que, sem dúvida, representará uma ameaça aos profissionais.

Andrade e Silva e cols, (1982) descrevem uma experiência de internação conjunta ${ }^{3}$ e concluem que a implantação de um serviço desse tipo depende, fundamentalmente, do preparo e motivação dos profissionais de saúde para atenderem e menos das condições geográficas e materiais de que a instituição dispõe. Acreditamos que além destes aspectos deve haver conviç̧ão, por parte da equipe, de que o familiar é um coadjuvante importante no restabelecimento do estado de saúde da criança ou, por outro lado, em casos onde isto não seja possível, como em doenças crônicas e terminais, é um agente colaborador no enfrentamento da situação, beneficiando a criança, a equipe e a si próprio.

Na ausência de disponibilidade para mudanças, mesmo sob ótimas condições, a intenção em se admitir pais pode resultar desastrosa para todos. Segundo Hardgrove \& Dawson (1972), devido a resistências tanto da administração, quanto do pessoal que atua mais diretamente ligado ao paciente, estas mudanças tão necessárias para as crianças e suas famílias, são postergadas indefinidamente.

Nas décadas de 70 e 80 , muitas instituições ocuparam-se em enfatizar a prática de alojamento conjunto, implementando programas do tipo mãe-acompanhante e mãe-participante (Lisboa, 1973; Andrade e Silva e cols, 1982). Esse fato levou os pesquisadores a se preocuparem com as relações entre equipe e família (Crepaldi, 1989; Ranna \& Okay, 1980; Ranna; 1987), tendo em vista que a presença desta última implementou uma nova dinâmica ao contexto hospitalar.

Nos últimos anos, porém, constatamos que há uma preocupação de se conhecer como a família vê sua inserção no espaço institucional, o que julga

\footnotetext{
${ }^{3}$ Este termo é utilizado para designar um tipo de hospitalização que mantém um dos familiares durante vinte e quatro horas na enfermaria, o que também é chamado de alojamento conjunto, programa mãe acompanhante ou programa mãe participante.
}

Paidéia, FFCLRP-USP, Rib. Preto, Fev/Ago 98. 
ser um bom atendimento, que representações tem sobre o binômio saúde-doença e como gostaria de participar do atendimento (Brunnquel \& Koren, 1991; Cameron, Snowdon e Orr, 1992; Crepaldi, 1995; Diehl , Moffitt e Wade, 1991; Knafl, Breitmayer, Gallo e Zoeller, 1992; Miles \& Maths, 1991) sendo dada à família não apenas a chance de acompanhar a criança, mas de interferir, efetivamente, nos rumos da atenção que é fornecida a ela própria e ao filho.

Neste sentido, julgamos cruciais os estudos de representação, tendo em vista os atores sociais envolvidos no cenário hospitalar, quer sejam: criança, família e equipe. A hospitalização força o encontro de pelo menos dois grupos importantes: a família e a equipe. Tal configuração costuma provocar desencontros entre as categorias do discurso, da equipe e dos familiares, um desencontro semântico e social que prejudica a atenção destinada aos usuários, dificultando o engajamento destes no atendimento, interferindo no grau de satisfação destas pessoas para com a instituição, além de dificultar o trabalho da equipe.

O estudo das representações que a família e equipe apresentam no contex to hospitalar tem sido a questão que centralizada os últimos trabalhos de pesquisa que temos desenvolvido. Estudamos primeiro as representações da família sobre doença e hospitalização, bem como a avaliação da assistência recebida e do trabalho da equipe (Crepaldi, 1995) e, posteriormente, como os profissionais representam os usuários, bem como suas expectativas em relação aos mesmos (Crepaldi, 1997).

Relataremos, a seguir, o primeiro trabalho citado, para exemplificar a importância destes estudos no cotidiano institucional.

\section{Sobre as representações sociais da família acerca da doença}

Segundo Jodelet (1984) as representações apresentam-se sob as mais variadas formas, que podem ser mais ou menos complexas. São categorias que servem para classificar as situações, os objetos, os indivíduos com quem temos relações; são teorias que permitem preceituar sobre os fenômenos da vida cotidiana. São imagens que traduzem um conjunto de significações; são sistemas de referência que nos permitem interpretar o que nos chega; são maneiras de dar um sentido ao desconhecido. Trata-se de atividade mental de indivíduos e grupos, destinada a fixar suas pertenças sociais, para relacionarem-se aos fatos, objetos e situações que lhes dizem respeito.

É, portanto, de um conhecimento chamado de "ingênuo", natural, espontâneo, do "senso comum", para distinguí-lo do saber científico. É uma noção prática que nos permite teorizar e apreender os eventos da nossa vida 
cotidiana, a partir das informações que circulam através dela.

Moscovici (1984) considera que o ato de denominar o objeto desconhecido faz parte da construção de uma representação, pois, desta forma, o sujeito estará tirando tal objeto de uma situação de anonimato que o intriga, incluindo-o num universo já conhecido.

Ser sujeito de uma doença, de um infortúnio, para quem quer que seja, é um fato infinitamente injusto e que necessita de sentido, de compreensão a partir de uma cadeia de causas e efeitos, isto é, precisa ser explicado (Sindzingre, 1991). Os familiares da criança que adquiriu uma doença, têm a mesma necessidade de atribuição de sentido, pois sentem-se inteiramente envolvidos e precisam encontrar uma razão para o acontecimento.

Hoje em dia a doença é um "assunto" que diz respeito quase que totalmente à instituição médica e ao saber biomédico, mas por outro lado é um fenômeno que ultrapassa os limites deste saber, quando nos voltamos para os diferentes significados que indivíduos ou grupos sociais the atribuem.

Pesquisas que tratam das representações sociais de saúde e doença (Herzlich, 1969; D'Houltaud, 1976; Aiach \& Philippe, 1980; Jodelet, 1985; Pierret, 1985 e Queiroz, 1991) têm evidenciado que as explicações que a medicina atribui à doença, através das categorias do discurso médico, na maioria das vezes, não satisfaz os sujeitos, que querem sempre encontrar a razão "mais profunda" do seu infortúnio.

Para Herzlich (1984) a doença é um acontecimento que pode ameaçar, modificar ou transformar, totalmente, e às vezes de forma irreversível, a vida pessoal e coletiva dos sujeitos. É um evento que necessita ser explicado pelo indivíduo e por uma sociedade inteira.

Além de estar circunscrita à singularidade do sujeito, a doença é também um fato social, sua natureza e sua distribuição são diferentes dependendo da época, das sociedades e das condições sociais (Herzlich, 1991). A peste, a tuberculose, o alcoolismo, a sífilis, cada uma a seu tempo, se constituíram em "flagelos sociais", assim como o são, hoje em dia, a Aids e o câncer. Todas são doenças que desencadearam uma mobilização muito grande no mundo todo, $\mathrm{e}$ não é por acaso que todas as sociedades elaboraram, sobre a doença, enunciados mais ou menos sofisticados.

Queiroz (1991), em uma pesquisa realizada em Paulínia, sobre as representações de doença e saúde, estudou uma população de 42 famílias da classe trabalhadora, usuárias dos serviços de saúde pública, destinados à comunidade. Verificou que a doença é definida como a impossibilidade de trabalhar e suas causas têm várias origens: nervosismo, principalmente na mulher, que se encontra ligado à instabilidade econômica e à falta de perspectivas, no que se refere à melhora de condições de vida. Outro fator importante diz res- 
peito ao destino e à natureza, ou a Deus. Aparecem também, menos freqüentemente, as causas alimentares, falta de higiene e condições climáticas, poluição, e extravagâncias pessoais, relacionadas com o contágio e a bebida.

O trabalho de pesquisa que fizemos no Instituto da Criança do Hospital das Clínicas da USP (Crepaldi, 1995), corrobora algumas destas afirmações como veremos a seguir. Investigamos as representações sociais que as famílias de crianças hospitalizadas, acometidas por doenças crônicas, têm sobre a doença e a hospitalização, limitando-nos no presente artigo aos resultados parciais relativos às representações da doença.

A pesquisa foi realizada na enfermaria de Patologia Geral do Instituto da Criança, que era também chamada de Grupo Geral. Nesta Unidade as famílias participavam de diversas atividades, havendo algumas especialmente destinadas à elas, como o Programa mãe-participante, que visavam fundamentalmente a veiculação da informação. Para por em prática esta medida, de forma sistematizada, a equipe utilizava-se de técnicas grupais.

A população estudada constituiu-se de 38 famílias, perfazendo um total de 50 participantes, e a metodologia de coleta de dados envolveu uma combinação de técnicas: observação participante de campo, entrevistas abertas e entrevistas semi-estruturadas, além de observação sistemática de sessões de grupo de pais e de acompanhantes. Os dados da observação participante de campo foram registrados em um diário de campo, aqueles relativos à observação sistemática foram registrados em audio-cassete e manualmente, enquanto os demais foram registrados em audio-cassete, sendo transcritos posteriormente. Para as análises de dados, utilizou-se técnicas de análise enunciativa do discurso (Austin, 1970).

\section{Resultados}

Em primeiro lugar constatou-se que, em se tratando de crianças, o que caracteriza o estado de doença é a incapacitação para o brinquedo, o estado de prostração que se opõe à vivacidade e atividade da criança, o prejuízo em seu desenvolvimento, somados ao aparecimento do sintoma ou conjunto de sintomas. $\mathrm{O}$ brinquedo eqüivale à principal atividade da infância, assim como $o$ trabalho o é para os adultos, como mostrou Queiroz (1991).

Os pais reconhecem a instituição médica como aquela que pode decifrar os sintomas que a criança apresenta, pois têm necessidade de encontrar uma definição para a doença, insistem para que esta seja nomeada e todos os esforços são empreendidos por eles para que isto ocorra. A descrição dos 
sintomas é o ponto de partida. Descrever, na verdade, é o que está ao alcance deles. Querem decodificar o que está ocorrendo, mas por sentirem-se limitados para alcançar este objetivo, delegam ao médico a tarefa de auxiliá-los neste empreendimento.

A representação da doença da criança é construída pelos pais, tendo em vista uma multiplicidade de fatores que se fundem e se entrelaçam, para dar um corpo, uma estrutura a esta construção. Tudo que viram e ouviram, ao longo da vida, sobre as doenças chamadas "infantis" e crianças que estão doentes; imagens e significações que acumularam, advindas do grupo social ao qual pertencem; a vivência tão concreta e presente, de ter um filho que nasceu doente ou que ficou doente e que necessita de hospitalização, concorrem para esta construção.

Não se pode dizer que a visão que nossos sujeitos apresentavam sobre a doença, no momento da internação, estava isenta da influência da medicina oficial. Queiroz (1991) afirma também, que nos últimos quinze anos assistimos à "medicalização" das classes populares, tendo em vista que os serviços de saúde tornaram-se disponíveis a todos através da rede pública. Em sua pesquisa, em Paulínia, não encontrou uma única família que não fizesse uso costumeiro de serviços médicos. Seus entrevistados mostraram-se totalmente familiarizados com as consultas médicas, nomes de doenças e medicamentos. Portanto, esta é mais uma variável que exerce influência sobre a construção da representação.

Em nosso estudo, também constatamos que os sujeitos tinham uma certa familiaridade com a medicina oficial, anterior ao aparecimento da doença. Além disso, em sua maioria, já haviam passado pela experiência de uma ou mais internações da criança, em outros hospitais ou em enfermarias do próprio Hospital das Clínicas. Nestas ocasiões, receberam as mais diversas informações. Assim, o que traziam logo que chegavam, era um conjunto de idéias, percepções, imagens e opiniões, que elaboraram em torno da doença do filho.

Aliados ao conjunto de variáveis em questão, apresentavam grande ansiedade e muitos temores advindos da situação de doença e de ter que delegar ao hospital a tarefa de cuidar da criança.

Apresentamos a seguir uma lista de categorias e suas respectivas subcategorias, que organizam o conteúdo representacional das falas, para em seguida descrever cada uma delas.

1. Definição da doença: denominação da doença, os sintomas, história da doença, sintomas protótipos, ausência dos sintomas, melhora dos sintomas, sintomas psicológicos, efeitos da medicação. 
2. A causa da doença: fatores endógenos, fatores exógenos, fatores ligados aos pais, combinação de fatores.

\section{As conseqüências da doença:}

a) A hospitalização: no Pronto Socorro, o segundo começo na enfermaria, os sentimentos dos pais, o hospital, a cidade grande, a integração do familiar.

b) A família e a hospitalização: a família dividida, a doença da família, a família e o trabalho.

O aparecimento do sintoma é condição fundamental para que o estado de doença seja admitido e a primeira preocupação da família, logo que chegava na enfermaria, era a de denominar a doença, conhecer o diagnóstico e as suas causas. Para eles a alta do hospital estava, muitas vezes, condicionada a esta denominação.

A nomeação da doença era considerada importante pois os familiares acreditavam que conhecendo-a poderiam proteger a criança de exames invasivos, poderiam responder aos parentes e amigos sobre a criança, pois a doença é um evento que o sujeito partilha com seu grupo social. Outro fator importante a se considerar é que a ausência de nome, do diagnóstico, costuma provocar suspeita, deste mesmo grupo, sobre uma possível gravidade da doença, acarretando no afastamento das pessoas por medo de um suposto contágio. Assim, enfrentar uma realidade muito dura, advinda de um diagnóstico desfavorável, mostrou-se até mesmo menos penoso do que enfrentar o desconhecimento da doença e a incerteza sobre o seu desfecho.

Conhecer o nome e as causas da doença é visto como uma obrigação dos pais, além de ser uma forma de alívio da culpa que sentem sobre o fato de que poderiam tê-la causado, por negligência nos cuidados, pelo fato de serem pobres, e portanto terem poucas condições de fornecer uma boa assistência ao filho, ou por hereditariedade.

Mesmo que se tratasse de reinternação, muitas vezes o familiar não tinha conhecimento do nome e tampouco da patologia. No caso de saber o nome, não conseguia atribuir-lhe um sentido, em outras vezes, a nomeação e a explicação da doença, quando conhecidas, baseavam-se na sua vivência com a criança doente e com as conseqüências da doença, ou seja, no seu background informacional, construído a partir de sua experiência de vida.

A história da doença, que sabiam contar com detalhes, era na verdade, a história dos sintomas, quando e como apareceram, estratégias encontradas para lidar com eles e que sentimentos mobilizaram. Os sintomas podem se 
configurar ainda, como protótipos para se pensar certas doenças. Manchas são associadas à aids, palidez e barriga grande estão associadas à vermes, prejuízo na marcha está associado à poliomielite etc.

Se os sintomas começarem a desaparecer é sinal de que a criança está sarando e a ausência deles significa ausência de doença, ainda que se trate de doenças muito graves. Mesmo conhecendo a gravidade da enfermidade a família utiliza-se desta representação, o que, muitas vezes, pode estar servindo como um mecanismo de negação da doença e da situação difícil que ela encerra.

A situação de doença e hospitalização do filho pode, ainda, desencadear ou agravar sintomas psicológicos nos demais membros da família. Os efeitos da medicação podem ser benéficos, como o soro e as vitaminas, ou nocivos, como os diuréticos e antibióticos, pois enfraquecem-na.

As causas da doença estão ligadas à fatores endógenos, exógenos e fatores ligados aos pais. Os fatores endógenos são inerentes à própria criança e são citados com menor frequiência, o exógenos estão presentes no ambiente, são concretizáveis, como as pessoas do convívio, os médicos, os vírus e as vacinas. Os fatores ligados aos pais pressupõem que a doença tenha se instalado devido a uma causa, direta ou indiretamente, ligada à eles próprios, o que gera muita culpa. Muitas vezes esta causa advém de uma combinação destes fatores, o que apareceu com mais freqüência neste trabalho.

A principal consequiência da doença, para os sujeitos, foi a hospitalização, pois trata-se de um acontecimento que altera completamente a vida familiar, trazendo ansiedade e incertezas. A começar pelo Pronto Socorro, a hospitalização já se configura como experiência negativa, pois promove a vivência de muitas situações de sofrimento, quer seja do filho ou de outras crianças. Uma vez encaminhados à enfermaria, o que denominamos de segundo começo, os pais encontram uma outra equipe e uma nova situação, e por mais que recebam muitas informações sentem-se confusos. Atribuem ao hospital a experiência negativa de hospitalização, alegando que o espaço é precário, que por ser um hospital escola temem serem usados como objeto de aprendizagem, além de alegarem que os médicos são jovens. Em segundo lugar apontam fatores externos ao hospital, como responsáveis pela experiência negativa, como o fato de terem que enfrentar uma cidade grande como São Paulo. Aos poucos, porém, o familiar consegue conviver com a situação, integrando-se às atividades, à medida em que vai compreendendo o que se passa consigo mesmo e com a criança, e vai conhecendo melhor o contexto hospitalar.

Outra consequiência importante é a divisão da família na ausência da

Paidéia, FFCLRP-USP, Rib. Preto, Fev/Ago 98. 
mãe, que é a pessoa que, geralmente, permanece no hospital. Esta divisão traduz-se pelo temor da perda da afiliação familiar e por sentimentos de desamparo e impotência.. Há alterações de papéis familiares e os outros filhos sentem-se abandonados. Podem, ainda, apresentar sintomas orgânicos ou psicológicos que aparecem em consequiência da situação nova, ou agravados por ela quando preexistentes.

O vida familiar pode também, ser prejudicada pela perda do trabalho de um ou ambos os pais.

Consideramos que o conhecimento destas representações é tão importante para a equipe de saúde, que prescindir dele torna muito prejudicada a interação com a família e, consequentemente, com a criança. Convivendo com a equipe da enfermaria, durante oito horas diárias por um longo período, pudemos constatar que tratava-se de um grupo extremamente interessado em comunicar-se com a família e sobretudo informá-la o máximo possível sobre o que estava ocorrendo com a criança, a doença, os exames, procedimentos médicos e de enfermagem. Um dos objetivos do atendimento destas famílias era poder corrigir o que chamavam de "idéias erradas" que aprenderam "popularmente", em outras palavras, suas representações. O que observamos também é que estas representações determinavam, muitas vezes, uma forma de se comportar, do familiar, cujo entendimento era difícil para a equipe. Em certos casos, a fidelidade ao conteúdo representacional era tão forte que nem mesmo muitas explicações científicas, dissuadiam o familiar de comportamentos que a equipe julgava inadequados.

\section{Conclusão}

A partir deste estudo concluímos que a preparação da equipe para atender bem a família se inicia pela compreensão da identidade desta, de sua pertença social, da informação acerca do que se passa com ela. Noutras palavras, pelo conhecimento das representações sociais acerca de uma variedade de fenômenos com os quais seus membros estão envolvidos e, pela compreensão dos seus sentimentos. Por outro lado, é importante que os profissionais saibam identificar e reconhecer seus próprios sentimentos, freqüentemente mobilizados por situação tão adversa como a de doença e suas implicações, além de conhecer também seus conteúdos representacionais, presentes no exercício de suas tarefas.

A família, tanto quanto a criança, é afetada pela doença e conseqüente internação e suas reações podem ser as mais diversas. Alguns apresentam medos reais que são proporcionais a gravidade da doença, outros sentem culpa 
por pensar poderem ter influenciado para que a doença se instalasse, como mostramos e outros ainda, podem demonstrar ansiedade exagerada.

A hospitalização se configura como uma situação de crise que pode interferir na capacidade que os pais têm para dar apoio à criança e para lidar com o ambiente. Os pais podem expressar sua ansiedade em forma de atitudes críticas dirigidas à equipe. Se esta não estiver atenta às prováveis razões dessa hostilidade pode se antagonizar com eles e a comunicação se torna muito difícil. A doença, principalmente quando crônica, grave e sobretudo em estágio avançado, suscita tensões, ansiedade e culpa que muitas vezes provocam conflitos entre familiares e equipe. Estes geralmente se traduzem em "condutas de vigilância, desconfiança, exigências excessivas e hostilidade" (Maldonado, 1986, p.7).

É importante, portanto, que a equipe conheça estes mecanismos a fim de que possa atender a clientela de forma adequada, sem que para isto tenha que ver sacrificados alguns dos seus segmentos, e estar atenta para o fato de que as representações da doença, hospitalização e da própria equipe podem estar na origem destes conflitos.

Preocupados em melhorar as relações entre equipe e familiares, beneficiando consequentemente a criança, alguns autores discutem formas possíveis de se lidar com os pais e o papel que devem exercer no hospital (Campbell \& Patterson, 1995; Crepaldi, 1989; Kazak, 1989; Drotar, 1997). A grande maioria deles salienta a importância da informação. Recomenda-se que o médico diga aos pais tudo o que sabe sobre a criança e tudo o que pretende fazer. Sugere-se que as informações sejam repetidas, pois sempre que a família entende o motivo da adoção de certas atitudes torna-se mais cooperativa e menos preocupada.

É muito importante que a comunicação entre equipe, família e criança seja estabelecida de forma positiva. O papel da equipe de enfermagem, segundo Lima, Kakehashi e Barbosa (1985) é esclarecer as dúvidas dos pais e ajudálos sem, no entanto, os julgar. É preciso favorecer a presença da mãe ou substituta e receber a criança e a família tentando estabelecer uma relação empática com eles (Lima e cols, 1985). Estas recomendações sem dúvida, aplicam-se aos outros membros da equipe, além das enfermeiras, pois numa unidade onde as categorias profissionais são diversificadas, favorecer a participação dos pais é incumbência de todos.

Atendidas estas condições, a hospitalização pode vir a ser, para a criança e sua família, uma experiência benéfica, podendo inclusive proteger e promover o desenvolvimento da criança, mesmo que esteja prejudicado pela doença. 


\section{Referências Bibliográficas}

Aiach, P. \& Philippe, A. (1980). Différenciations socio-culturelles en matière d'information médicale et d'intérêt pour les questions de santé et de maladie. Revue Internationale d'Education pour la Santé, 23(1),12-27.

Alves, M. (1981). A morte do filho: observação psicológica de familias de crianças leucêmicas. Dissertação de Mestrado, Fundação Getúlio Vargas, Rio de Janeiro.

Andrade e Silva, P.S.L; Aguiar, A.A; Souza, I. S. \& Almeida, I.N. (1982). Internação conjunta (IC) mãe-filho em enfermaria coletiva de hospital conveniado com o INAMPS. Jornal de Pediatria, 52(6), 391-394.

Austin, J.L. (1970) Quand dire c'est faire, Paris: Seuil.

Ayer, A.H. (1978). Is partnership with parents really possible? Maternal child Nursing, New York, 3(2), 107-110.

Bowlby, J. (1952). Maternal care and mental health. Word Health Organization, Geneva: Palais de Nations.

Bowlby, J. (1960). Separation anxiety. The International Journal of Psychoanalysis. 41, 8 9-113.

Brunnquel, D. \& Koren, D.P. (1991). Emotions in pediatric emergencies: What we know, what we can do. Children's Health Care, 20(4), 240-247.

Cameron, S.J.; Snowdon, A. \& Orr, R.R. (1992). Emotions experienced by mothers of children with development disabilities. Children's Health Care, 21(2), 96-101.

Campbell, T. \& Patterson, J. (1995). The effectiveness of fammily intervenctions in the treatment of physical ilness. The Journal of Marriage and FamilyTtherapy, 21, 545-583.

Cleary, J; Gray, O.P.; Hall, D.J.; Rowlandson, P.H; Sainsburg, C.P.Q. \& Davis, M.M. (1986). Parental involvement in the lives of de children in hospital. Archives of Disease in Childhood, 61, 79-787.

Coffin, M.A.(1955).Visiting hours for parents. American Journal of Nursing, New York, 55(3), 329.

Crepaldi, M.A.(1989). Hospitalização infantil: estudo das interações familia-equipe hospitalar. Dissertação de Mestrado, Pontifícia Universidade Católica, Rio de Janeiro.

Crepaldi, M.A. (1995). Hospitalização na infância: representações sociais da familia sobre a doença e hospitalização de seus filhos em enfermaria pediátrica. 
Tesede Doutorado, Faculdade deCiências Médicas, UniversidadedeCampinas, Campinas.

Crepaldi, M.A. (1997). Representacões sociais dos profissionais sobre a família da criança hospitalizada. (relatório de pesquisa). Florianópolis: Universidade de Santa Catarina.

D'Houltaud, A. (1976). Les représentations de la santé: recherches dans un centre de bilan de santé en Lorraine. Revue Internationale d'Education pour la Santé, 19(2), 99-118.

Dielh, S.F.; Moffitt, K.A.; \& Wade, S.M. (1991). Focus group interview with medically complex needs: An intimate look at their perceptions and feelings. Children's Health Care, 20(3), 170-178.

Drotar, D. (1997). Relating parent and family functioning to the psychological adjustment of children with chronic health conditions. What have we learned? What do we need to know? Journal of Pediatric Psychology, 22, 229- 244.

Evans, A.E. (1975) Practical care for the family of a child with cancer. Cancer, 35, 871-875.

Fagin, C.M. (1962). Why not involve parents when children are hospitalized? American Journal of Nursing, New York, 62(6), 78-79.

Friedman, S.B. (1967). Care of the family of the child with cancer. Pediatrics, 40, 31-39.

Grunberg, J; Silva, D.; Sitkewich, A; Esquivel, N. \& Farias, Y (1981). El impacto en la dinámica familiar en la ausencia de la madre en el hogar durante la hospitalización conjunta con el hijo. Boletin Instituto Interamericano el NIÑO (Montevidéo), 216:45-51.

Hardgrove, C. B. \& Dawson, R. B. (1972) Parents and children in the hospital, Boston: Little Brown and Company.

Heffron, W.A; Bommelaere, K. \& Master, R. (1973)Group discussions with the parents of leukemic children. Pediatrics, 52, 831-840.

Herzlich, C.(1969)Santé et maladie: analyse d'une représentation sociale. Paris, Mouton. Herzlich, C. (1984) La problématique de la représentation et son utilité dans le champ de la maladie. Sciences Sociales et Santé, 2( 2), 71-84.

Herzlich, C. (1991) Médecine moderne et quête de sens:la maladie signifiant social. Em M. Auge, M. \& C. Herzlich (ed), Le sens du mal: antrhopologie, histoire, sociologie de la maladie (pp. 189-216). Paris: Éditions des Archives Contemporaines.

Hohle, B. M. (1957) We admit parents too. American Joumal of Nursing, 57(7), 65-867. 
Issner, N. (1972). The family of the hospitalized child. Nursing Clinics North America, Philadelphia, 7(1), 5-12.

James, V.L. \& Wheler, W.E. (1969). The care - by- parent unity Pediatrics, $43,488-498$.

Jodelet, D. (1984). Representación social: fenómenos, concepto y théoría. Em S. Moscovici (Ed.) Psycologia social (pp. 469-494). Barcelona - Buenos Aires - México, Paidós.

Jodelet, D. (1985). Civils et brédins: rapport à la folie et représentation sociale de la maladie. Thèse de Doctorat d'État, EHESS, Paris

Kazak, A. (1989). Families of chronically ill childrens: a systems and social ecological model of adaptation and challenge. Journal of Consulting and Clinical Psychology, 57, 25-30.

Kazak, A. (1997). A contextual family/systems approach to pediatric psychology: introduction to the special issue. Journal of Pediatric Psychology, 22, 141-147.

Knafl, K.; Breitmayer, B.; Gallo, A. \& Zoeller, L. (1992). Parents' views of health care providers: an exploration of the components of a positive working relationship. Children's Health Care, 21(2), 91-95.

Lima, A.M.; Kakehashi, T.Y. \& Barbosa, V.L. (1985). A criança e a família frente a hospitalização. Enfermagem Moderna, 3(3), 45-52.

Lisboa, A.M.J. (1973). Programa de hospitalização conjunta mãe-filho. Jornal de Pediatria, Rio de Janeiro, 38(7-8):191-194.

MacCarthy, D. (1981) The under fives in hospital. Nursing Times, London, 77(30 suppl), 22-28.

Maldonado, M. T. (1986) A psicologia em hospital privado: dificuldades e possibilidades. Lisboa: Gradiva.

Miles, M.S. \& Mathes, M. (1991). Preparation of parents for the ICU experience: what are we missing? Children's Health Care, 20(3), 133-137.

Moscovici, S. (1984) The phenomenon of social representations. Em R.M.Farr \& S. Mosovici (Org). Social representations (pp 3-69). Cambridge: Cambridge University Press.

Nascimento, M.J.P. (1985). Participação dos pais na assistência à criança hospitalizada: opinião de enfermeiras do Recife. Revista Paulista de Enfermagem, São Paulo, 5(3), 119-126. 
Nolan, H. (1981). Hospitalization of infants and pre-schoolers. The Lamp, Sidney, 38(8), 29-35.

Osório, D.A.; Ferari, A.M.; Alonso, R. \& Cardoso, N. (1978). Hospitalización conjunta del hijo con su madre: programa de madre participante. Boletin Oficial Sanitario Panamericano, 84(3), 240-245.

Pierret, J. (1985). Construtions sociales du discours sur la maladie. Prévenir, 11,99-102.

Queiroz, M.S. (1991) Representações sobre saúde e doença: agentes de cura e pacientes no contexto do SUDS. Campinas: Editora da UNICAMP.

Ranna, W.(1987). Aspectos psicossociais da assistência à criança hospitalizada: vivência com grupos de crianças e de pais. Dissertação de Mestrado . Faculdade de Medicina, Universidade de São Paulo, São Paulo.

Ranna, W. \& Okay, Y.(1980). Grupos de pais de crianças e da equipe multiprofissional, e sua influência nas diretrizes da enfermaria geral de um hospital infantil. Pediatria (São Paulo), 2, 184-190.

Roy, S.C. (1968). Role cues for the mother of the hospitalized child. Em Ana Clinical Sessions (pp.199-206). New York, Appleton Century - Crofts.

Ryan, M. (1984). Mother care for children in hospital. British Medical Journal, $288,381-382$.

Schyff, G. (1979). The role of parents during their child's hospitalization. Australian Nursing Journal, Port Adelaide, 8(11), 57-61.

Sindzingre, N. (1991). La necessité du sens: l'explication de l'infortune chez les Senufo. Em M. Augé \& C. Herzlich (Ed.), Les sens du mal: anthropologie, historie, sociologie de la maladie, Paris: Archives Contemporaines.

Spitz, R.A. (1945) Hospitalism: an inquiry into the genesis of psychiatric condition in early childhood (I).The Psychoanalysis Study of the Child, 1, 53-74.

Spitz, R.A. \& Wolf, K.M. (1946). Anaclitic depression: an inquiry into the genesis of psychiatric condition in early childhood (II). The Psychoanalysis Study of the Child, 2, 313-342.

Thomas, N. \& Cordell, A.S. (1983). The dying infant: aiding parents in the detachment process. Pediatric Nursing, 9(5), 355-357. 